\title{
Detection of ESBLs, MBLs and AmpCs in Gram Negative Uropathogens in Tertiary Care Hospital
}

\author{
Fatima Amatullah*, Gandham Pavani and A.J. Nandeshwar
}

Department of Microbiology, Maheshwara Medical College, Telangana, India

\author{
*Corresponding author
}

\begin{tabular}{|l|}
\hline Ke y w o r d s \\
ESBL, MBL, AMP C, \\
Carbapenamases, $\beta$ \\
lactamases. \\
\hline Article Info \\
\hline $\begin{array}{l}\text { Accepted: } \\
\text { 12 September } 2017 \\
\text { Available Online: } \\
\text { 10 November } 2017\end{array}$ \\
\hline
\end{tabular}

A B S T R A C T
Urinary tract infections are common bacterial infections which vary from asymptomatic bacteriuria to cystitis and pyelonephritis. Infections with multidrug resistant gram negative bacilli have become a great concern as emerging $\beta$ lactamases like ESBLS, AmpC and MBLs are cause of multidrug resistance in gram negative bacilli. Thus, there detection is needed to prevent UTI and to decrease the hospital stay of patients. Aim of the study is to identify uropathogens causing urinary tract infection. To detect ESBLs, MBLs, AmpC producing isolates from urine. Cross sectional study of 300 urine samples was conducted in Mediciti Institute of Medical Sciences. The samples were processed and gram negative bacilli were identified as per Mackie McCarteny 14th edition. Detection of ESBLs, MBLs and AmpCs producing organisms among the isolates was done by both screening and confirmatory test as per CLSI guidelines. Out of 300 urine samples analyzed, prevalence of gram negative bacilli was $56.6 \%$. The predominant gram negative bacterial isolate was Escherichia coli 55.9\%, Klebsiella 26.5\% and Pseudomonas 9.4\%. Among these isolates $38.8 \%$ were ESBL producers, $2.35 \%$ MBL producers and 9.4\% were AmpC producers. Prevalence of gram negative pathogens in hospital area was $56.6 \%$, predominant isolate was Escherichia coli. ESBLs were the predominant $\beta$ lactomases produced.

\section{Introduction}

Urinary tract infections (UTI) are common bacterial infections associated with considerable morbidity and health care cost, with varied clinical spectrum of severity ranging from asymptomatic bacteriuria to cystitis and pyelonephritis to septic shock with multiorgan system failure. UTIs are specially problematic for women, $50-80 \%$ of women will suffer at least one episode of UTI in their lifetime and $20-50 \%$ of these women will have recurrent episodes. (1)

Urinary tract infections are classified as uncomplicated UTI and complicated UTI, depending on the factors that trigger the infections. Uncomplicated UTIs are associated with bacterial infections, most often Escherichia coli.

The bacteria can invade and cause a urinary tract infection by two major routes, ascending or haematogenous. In females the ascending route is more common and organisms originate from faecal or vaginal source.

Several studies regarding the prevalence and antibiotic susceptibility or resistance pattern of bacterial isolates in different settings 
established that community acquired urinary tract infections occurred in $85 \%$ of population while, hospital acquired infection in only $15 \%$ of cases.

Gram negative bacteria such as Enterobacteriaceae, Pseudomonas aeruginosa and Acinetobacter spp are able to cause serious infections especially in hospitalized patients.

Treatment of infections is often complicated due to the increasing bacterial resistance against different classes of antibiotics.

Infections with multidrug resistant gram negative bacilli have become a great concern as they are associated with higher morbidity, mortality, prolonged hospital stay and raising health care costs.

As emerging betalactamases (ESBLs, Ampc and carbapenamases) are main cause of multidrug resistance in gram negative bacilli. Detection of ESBL, MBL, and Ampc is needed to prevent resistant UTIs and to decrease the hospital stay.

\section{Materials and Methods}

Cross sectional study of 300 urine samples was conducted from Nov 2011 to Aug 2013, in Mediciti Institute of Medical Sciences. The samples were processed and the gram negative bacilli were identified by microscopy, culture and standard biochemical reactions as per Mackie McCarteny $14^{\text {th }}$ edition. $5-10 \mathrm{ml}$ of single clean catch midstream urine was collected from symptomatic patients of urinary tract infection (Table 2).

The container was labeled with date, name, number of patient and the time of collection and immediately transported to laboratory and processed without any delay in the microbiology laboratory at Mediciti Institute of Medical Sciences, Medchal.

All samples were processed by following technique Macroscopic appearance of urine was noted, whether it was turbid or clear.

\section{Microscopy}

Wet mount preparation: Wet mount of the urine for cytology was performed to screen for R.B.C, W.B.C bacteria and yeast cells. 5$10 \mathrm{ml}$ of well mixed urine was transferred to a labeled test tube. Centrifuged at 500-1000 rpm for 5 minutes. Supernatant was discarded. The sediment was remixed by tapping the bottom of the tube. One drop of the well mixed sediment was transferred to a clean slide covered with cover slip. The preparation was examined microscopically using the $10 \mathrm{x}$ and $40 \mathrm{x}$ objective with condenser iris closed sufficiently to give good contrast.

In wet mount $>10$ cells/HPF are significant for UTIs to process the specimen. In gram stain 1 cell/HPF in 7 fields corresponds to $10^{4}$ leucocytes $/ \mathrm{ml}$. For suggesting pyuria at least $10^{4}$ leucocytes must be present.

\section{Culture}

Each of the urine specimens was subjected to culture by the standard loop method and filter paper method. These specimens were inoculated on Blood agar, MacConkey agar, Cystine Lactose Electrolyte Deficient agar (CLED Himedia) agar. Culture plates were incubated aerobically at $37^{\circ} \mathrm{C}$ for $18-24$ hours.

\section{Semiquantitative analysis}

\section{Standard loop method}

Inoculating loop of standard dimension about $4 \mathrm{~mm}$ internal diameter and volume $(0.001 \mathrm{ml})$ 
of urine was taken. Loop full of well mixed uncentrifuged urine specimen was inoculated on Blood agar, MacConkey agar CLED agar. The culture plates were incubated at $37^{\circ} \mathrm{C}$ for 18-24 hrs. Bacterial counts were done by counting the number of colonies and multiplying the number of colony forming units (CFU) by 1000, to determine the number of microorganisms per milliliter in the original specimen. Colony count of $>10^{5}$ $\mathrm{CFU} / \mathrm{ml}$ was considered as significant bacteriuria.

The following biochemical tests were put up Mackie and McCartney 14th edition (39).

For gram negative isolates, colony was subcultred into peptone water and the following tests were performed: Hanging drop (for motility), catalase test, oxidase test, Indole test, Methyl red test, Vogues Proskauer test, Simmons citrate utilization test, Urease test, Triple sugar iron test, Nitrate reduction tests, Sugar fermentation tests for the following sugars: Glucose, Lactose, Sucrose, Maltose, Mannitol and Xylose, Phenylalanine Deaminase test, Amino acid decarboxylase test: Lysine, Arginine and ornithine, Hugh Leifson's Oxidation /Fermentation test.

\section{Testing for antibiotic susceptibility}

\section{Antibiotic testing by Kirby Bauer disc diffusion method}

The test organism was subcultured into peptone water and incubated for 4-6 hrs at $37^{0} \mathrm{c}$. The turbidity was standardized with 0.5 Mc Farlands and swabbed over $90 \mathrm{~mm}$ Mueller-Hinton agar plate. Antibiotic disc were placed at $15 \mathrm{~mm}$ from the edge of the plate and discs were evenly placed, that they were no closer than $25 \mathrm{~mm}$ from centre to centre. Plate was incubated at $37^{\circ} \mathrm{C}$ for $18-24$ hrs. Zones of inhibition were measured after incubation with a ruler and interpreted as per
CLSI guidelines. The commercially available antibiotics discs supplied by Himedia (Mumbai) were used.

\section{Antibiotics tested against gram negative bacilli}

Zones of clearance were measured after incubation with a ruler and interpreted as per Ampicillin $(10 \mu \mathrm{g})$, amikacin $(30 \mu \mathrm{g})$, cefotaxime $(30 \mu \mathrm{g})$, ceftazidime $(30 \mu \mathrm{g})$, nitrofurantoin $(30 \mu \mathrm{g})$, trimethoprim + suphamethoxazole $(1.25+23.75 \mu \mathrm{g})$, cephalexin $(30 \mu \mathrm{g})$, ciprofloxacin $(5 \mu \mathrm{g})$, ofloxacin $(5 \mu \mathrm{g})$.

\section{Extended spectrum $\beta$ lactamase detection}

Organisms resistant to third generation cephalosporins by Kirby Bauer disc diffusion method were selected for ESBL confirmatory tests. Antibiotics used were - ceftazidime (30 $\mu \mathrm{g})$, ceftazidime + clavulanic acid $(30 \mu \mathrm{g}+$ $10 \mu \mathrm{g})$.

\section{Confirmatory method}

\section{Disc potentiation test}

In this a pair of discs containing cephalosporin with and without clavulanic acid was placed on opposite sides of the same inoculated plate. The test organism was regarded as an ESBL producer if the zone of inhibition around the combination disk was at least $5 \mathrm{~mm}$ larger than that of the cephalosporin alone. (3)

\section{Detection of MBLs}

Testing organisms were inoculated on the Muller Hinton agar plates. A 0.5 M EDTA solution was prepared by dissolving $186.1 \mathrm{~g}$ of disodium EDTA in $100 \mathrm{ml}$ of distilled water and adjusting $\mathrm{P}^{\mathrm{H}}$ to 8.0. The EDTA solution was sterilized by autoclaving. 


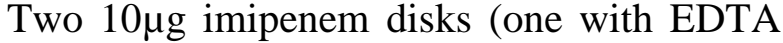
and other without) are placed on the surface of the muller hinton agar plate.

Inhibition zones of imipenem and their EDTA impregnated discs were compared after incubation at $37^{\circ} \mathrm{C}$. A zone size difference of greater than or equal to $7 \mathrm{~mm}$ with EDTA impregnated discs is taken as indicative of metallo $\beta$ lactamases production. (24).

\section{Detection of AMP C}

Double Disc Synergy Tests using $500 \mu \mathrm{g}$ was put up for all non-ESBLs producing strains using inhibitor of AmpC $\beta$ lactamases. Using Mueller Hinton plate for each test organism, a lawn culture was made, the disc of the inhibitor was placed in the centre and the distance between this disc and cefotaxime $(30 \mu \mathrm{g})$ and ceftazidime $(30 \mu \mathrm{g})$, one on either side from centre to centre, was kept as 15 $\mathrm{mm}$.

After overnight incubation at $37^{\circ} \mathrm{C}$, expansion of inhibitory zone of either one or both, ceftazidime and cefotaxime, towards the inhibitory discs was interpreted as positive results for production of $\mathrm{AmpC} \beta$ lactamases by the isolates (37).

\section{Results and Discussion}

Our study was undertaken to know the distribution and the antibiotic susceptibility pattern of uropathogens, isolated from patients in tertiary care hospital.

In our study female to male ratio was $2: 1$, $60 \%$ were female and $30 \%$ were male patients (female to male ratio was 2:1) (Table 4).

The present study correlated with study conducted by Marie-Vic-o et al., (4) in 1998, reported that majority of patients were female, the ratio between female and male was 4.6:1. In this study, urinary tract infections were most commonly found in the age group between 31-35 years. The present study was similar to Dimtrov et al., in 2003 who reported significant bacteriuria among young and middle age patients (20-40) years (Table $3)$.

In our study most of the isolated organisms were found to be sensitive to amikacin $(85.7 \%)$ and nitrofurantoin $(71.4 \%)$ and resistant to ampicillin (28.57\%) cotrimoxazole (57.1\%) Asad Khan et al., (41) in 2006 found that $90 \%$ of isolates were resistant to ampicillin followed by chloramphenicol (60\%) (Tables 6, 7 and 8).

In the present study, among the gram negative isolates, the maximum percentage of ESBLs were detected in Escherichia coli (42.85\%) followed by Klebsiella pnuemoniae (30\%). This data correlated well with the study conducted by Mohammed Akram et al., (40) in 2007 in JNMC Hospital, Aligarh, who detected $34.42 \%$ of E. coli, $27.3 \%$ Klebsiella pneumoniae to be the most prevalent ESBL producers in community acquired urinary tract infections.

Similarly, Nachimuth Ramesh et al., (32) in 2008 observed $71.5 \%$ of isolated were ESBL producers in hospital isolates. While Shukla $e t$ al., (42) in 2004 reported only $30.18 \%$ ESBL producers.

In our study we have observed $2.35 \%$ of Pseudomonas among gram negative isolates as MBL producers by imepenem, imepenem EDTA method (Figs. 1-3).

Gupta et al., (24) in 2006 conducted a study at Government medical college, Chandigarh and found $7.5 \%$ of pseudomonads and Acinetobacter were shown to be MBL producers with imepenem and imepenem EDTA method in concordance with present study (Tables 9 and 10). 
Table.1 Distribution of patients

\begin{tabular}{|l|l|}
\hline Patient distribution & No. of patients \\
\hline Inpatient & $180(60 \%)$ \\
\hline Outpatient & $120(40 \%)$ \\
\hline Total & 300 \\
\hline
\end{tabular}

A total of 300 urine samples were screened for pathogenic organisms. Out of which $40 \%$ of samples were from out patient and $60 \%$ of samples are from inpatient.

Table.2 Symptom analysis of UTI

\begin{tabular}{|l|l|l|}
\hline Symptoms & $\mathrm{M}=120$ & $\mathrm{~F}=180$ \\
\hline Burning micturation & 50 & 45 \\
\hline Frequency & 25 & 35 \\
\hline Fever & 20 & 40 \\
\hline Lower abdomen pain & 10 & 35 \\
\hline
\end{tabular}

In all patients burning micturition is most common presenting symptom.

Table.3 Age wise distribution of clinically suspected cases of UTI

\begin{tabular}{|l|l|}
\hline Age $(\mathbf{Y r s})$ & Number of patients \\
\hline 10-19 Years & $40(13.33 \%)$ \\
\hline 20-29 Years & $98(32.6 \%)$ \\
\hline 30-39 Years & $120(40 \%)$ \\
\hline 40-49 Years & $30(10 \%)$ \\
\hline 50-59 Years & $12(4 \%)$ \\
\hline
\end{tabular}

Out of 300 patients with suspected UTI maximum number (40\%) of patients are from age group of $30-39$ years.

Table.4 Sex wise distribution of cultural results of UTI

\begin{tabular}{|l|l|l|l|}
\hline & Culture +ve & Culture - ve & Total=300 \\
\hline Male & $60(35.29 \%)$ & $60(54.5 \%)$ & $120(40 \%)$ \\
\hline Female & $110(64.7 \%)$ & $70(63.6 \%)$ & $180(60 \%)$ \\
\hline
\end{tabular}

Out of 300 patients selected for study $40 \%$ are males, in which $35.29 \%$ are culture positives, $60 \%$ are females, in which $64.7 \%$ are culture positives, indicating maximum incidence of UTI in females.

Table.5 Bacteriological profile of UTI

\begin{tabular}{|l|l|}
\hline Gram negative isolate & No. of isolates \\
\hline Escherichia coli & $95(55.88 \%)$ \\
\hline Klebsiella & $45(26.47 \%)$ \\
\hline Pseudomonas & $16(9.4 \%)$ \\
\hline Proteus & $8(4.7 \%)$ \\
\hline Citrobacter & $6(3.5 \%)$ \\
\hline Total & $170(100 \%)$ \\
\hline
\end{tabular}

Out of 300 samples studied for UTI, predominant isolate was E. coli (55.88\%), followed by Klebsiella (26.47\%). 
Table.6 Antibiotic susceptibility pattern of test isolates

\begin{tabular}{|l|l|}
\hline Antibiotics & Sensitivity \\
\hline Ampicillin & $35.7 \%$ \\
\hline Amikacin & $85.7 \%$ \\
\hline Nitrofurantoin & $71.4 \%$ \\
\hline Cotrimoxazole & $57.1 \%$ \\
\hline Cephalexine & $76.1 \%$ \\
\hline Ceftazidime & $60 \%$ \\
\hline Cephotaxime & $50 \%$ \\
\hline Gentamicin & $85.7 \%$ \\
\hline Cepodoxime & $70.4 \%$ \\
\hline
\end{tabular}

Antibiogram of isolates showed maximum sensitivity to amikacin \& Gentamicin $(85.7 \%)$, followed by cephalexin $(76.15 \%)$.

Table.7 Antibiotic susceptibility pattern of Escherichia coli

\begin{tabular}{|l|l|}
\hline Ampicillin & $30 \%$ \\
\hline Amikacin & $87 \%$ \\
\hline Nitrofurantoin & $80 \%$ \\
\hline Cotrimoxazole & $60 \%$ \\
\hline Cephlexine & $51.4 \%$ \\
\hline Ceftazidime & $47.1 \%$ \\
\hline Cephotaxime & $50 \%$ \\
\hline Gentamicin & $85.7 \%$ \\
\hline Cepodoxime & $70.4 \%$ \\
\hline Ciprofloxacin & $45 \%$ \\
\hline Imepenem & $37 \%$ \\
\hline
\end{tabular}

In antibiogram of Escherichia coli which is predominant isolate in study maximum sensitivity was noted for Amikacin (87\%) followed by Gentamicin and nitrofurantoin $(85.7 \%, 80 \%)$ least with ampicillin $(30 \%)$.

Table.8 Antibiotic susceptibility pattern of Klebsiella species

\begin{tabular}{|l|l|}
\hline Ampicillin & $20 \%$ \\
\hline Amikacin & $87 \%$ \\
\hline Nitrofurantoin & $76 \%$ \\
\hline Cotrimoxazole & $60 \%$ \\
\hline Cephlexine & $51 \%$ \\
\hline Ceftazidime & $60 \%$ \\
\hline Cephotaxime & $58 \%$ \\
\hline Gentamicin & $86 \%$ \\
\hline Cepodoxime & $70.4 \%$ \\
\hline Ciprofloxacin & $46 \%$ \\
\hline Imepenem & $35 \%$ \\
\hline
\end{tabular}

In antibiogram of Klebsiella which is second predominant isolate in study maximum sensitivity was noted for Amikacin (87\%) followed by Gentamicin and nitrofurantoin $(80 \%, 76 \%)$ least with ampicillin $(20 \%$.) 
Table.9 Prevalence of ESBL, MBL and Amp C: No. Tested =170 / No. Detected=86

\begin{tabular}{|l|l|}
\hline Resistance pattern & Prevalence of resistance $\mathbf{n = 1 7 0}$ \\
\hline ESBL & $66(38.82 \%)$ \\
\hline MBL & $4(2.35 \%)$ \\
\hline AmpC & $16(9.41 \%)$ \\
\hline Total & $86(50.58 \%)$ \\
\hline
\end{tabular}

Among the isolates in present study $38.82 \%$ are ESBL producers, $2.35 \%$ are MBL producers and $9.41 \%$ are Amp C producers.

Table.10 Organism wise prevalence of ESBL, MBL and AmpC in different isolates

\begin{tabular}{|l|l|l|l|}
\hline Organism & ESBL & MBL & AmpC \\
\hline Escherichia coli $\mathrm{N}=95$ & $40(42.1 \%)$ & - & $12(12.63 \%)$ \\
\hline Klebsiella $\mathrm{N}=45$ & $20(44.44 \%)$ & - & $3(6.66 \%)$ \\
\hline Pseudomonas $\mathrm{N}=16$ & $2(12.5 \%)$ & $4(25 \%)$ & - \\
\hline Proteus $\mathrm{N}=8$ & $2(25 \%)$ & - & - \\
\hline Citrobacter & $2(33.3 \%)$ & - & 1 \\
\hline Total & 66 & 4 & 16 \\
\hline
\end{tabular}

Among the ESBL producers predominant isolate is Klebsiella, and Ampc predominant isolate is Escherichia coli.

Fig.1 Detection of ESBL

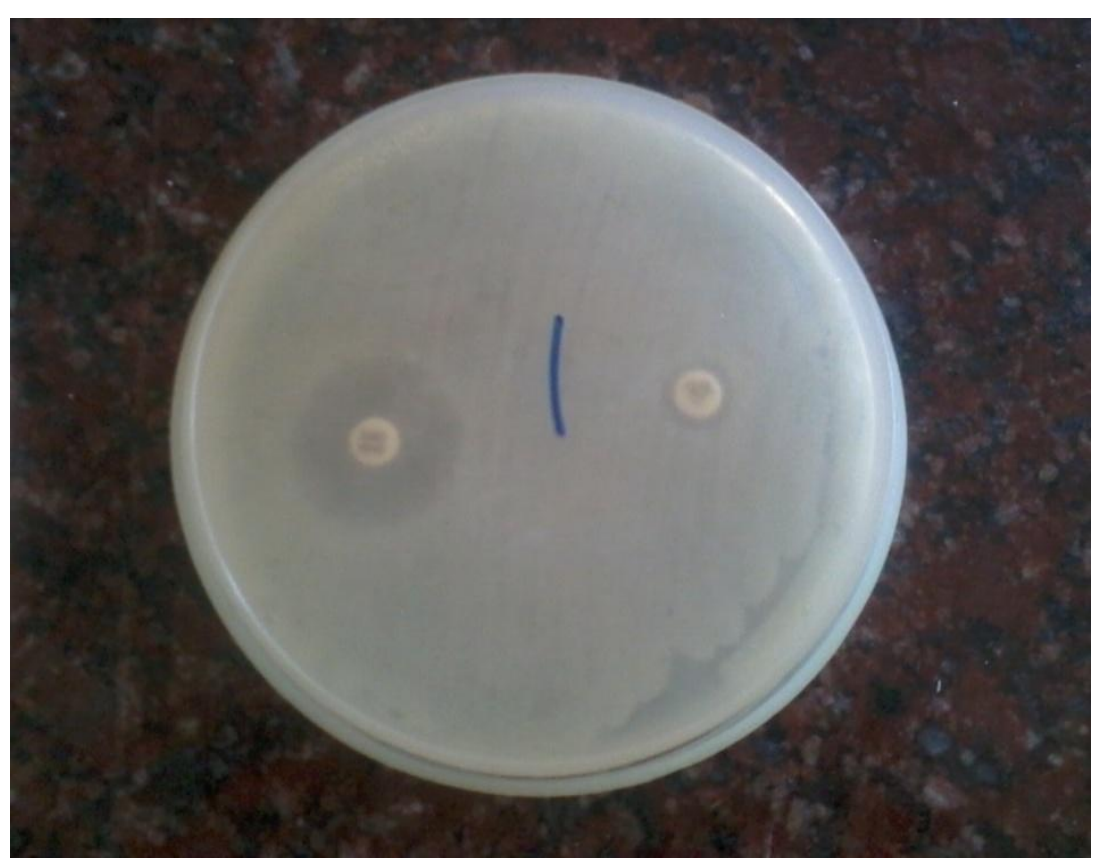


Fig.2 Detection of MBL

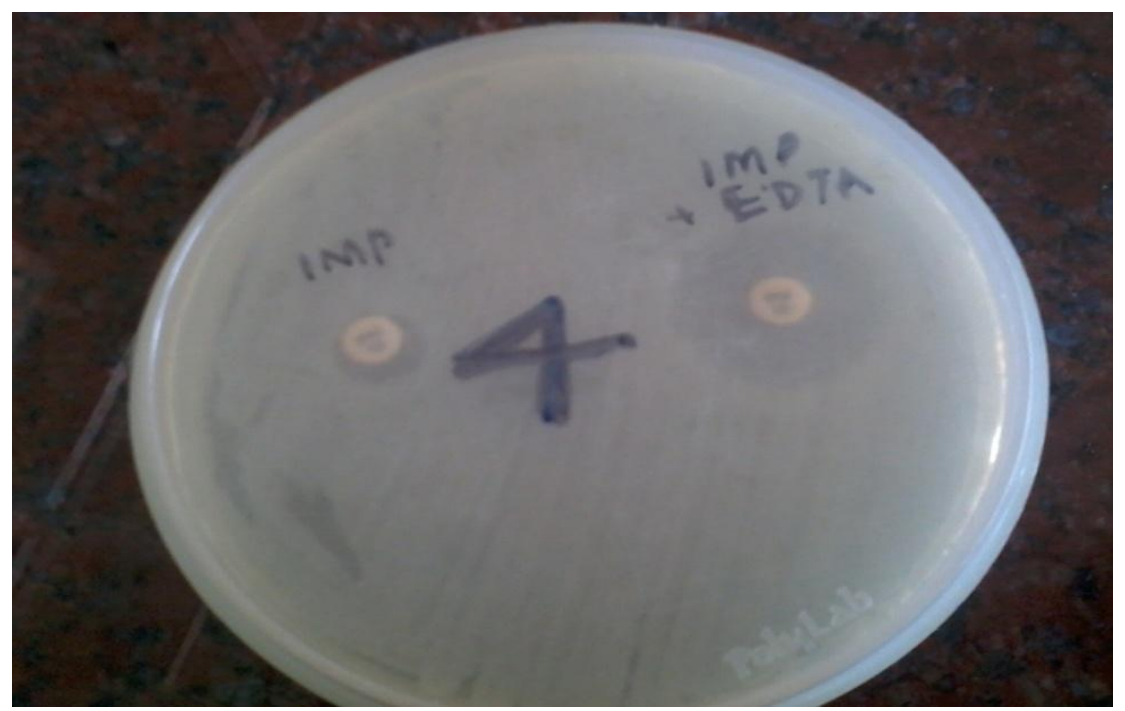

Fig.3 Detection of Amp C

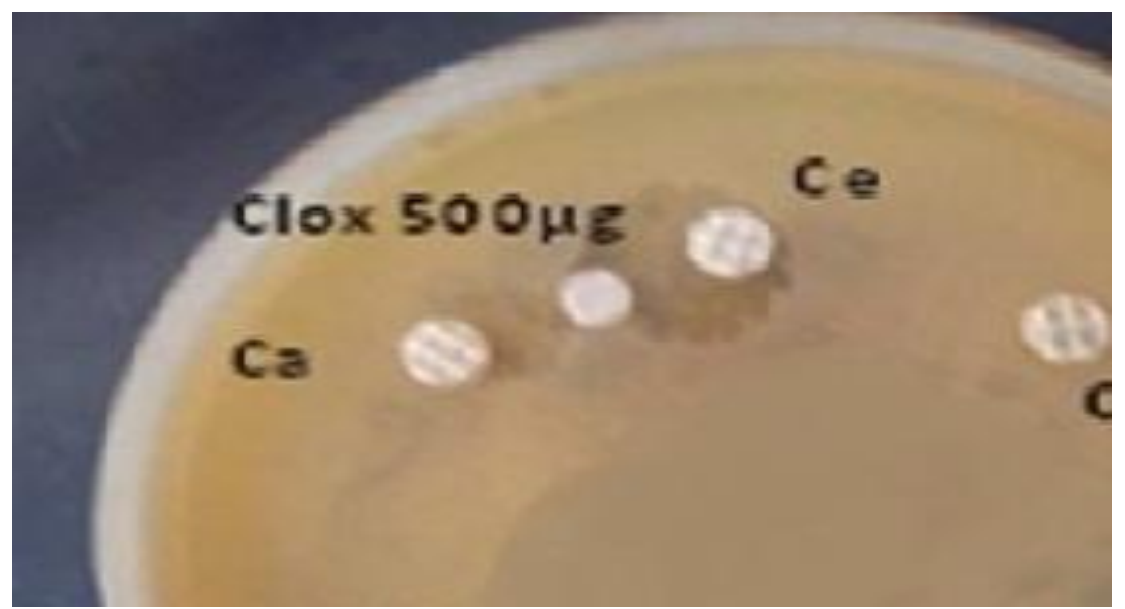

In our study $9.4 \%$ AmpC producers were isolated, by double disc synergy method, with cefotaxime, cefatazidime and cloxacillin.

Sasirekha Bakthavatchalu et al., (38) in 2011 conducted a study at centre of postgraduate studies in Jain University and found 5.4\% Amp c producers out of 259 isolates by CLSI double disc diffusion method and it is in concordance with present study. To summarize, the prevalence of urinary tract infections and antibiotic resistance pattern varied from country to country, place to place and time to time. The prevalence of ESBL, MBL and AmpC $\beta$ lactamases also varied in different places. It ranges from $0-100 \%$ in different reports. Other contributing factor affecting the prevalence is increased usage of $3^{\text {rd }}$ generation cephalosporin antibiotics in clinical practice. A continuous surveillance is therefore essential along with prudent use of implicated antibiotics.

\section{Acknowledgement}

Thanks to management of hospital, microbiology department Dr. Pavani and Dr. A.J. Nandeshwar for their support, to technical staff also for their co-ordination and to 
everybody associated to make it a grand success.

\section{References}

1. J.Agarwal, $S$ Srivastava, $M$ Singh.2012 .Pathogenomics of uropathogenic Escherichia coli Indian journal of Medical Microbiology ,30 (2):141-9.

2. S Baby padmini , B Appalaraju, K R Mani etal. 2008 .Detection of Enterobacteriacea producing CTX - M Extended spectrum beta lactamases in tertiary care hospital in south India, 26 ( 2 ) : 163 -6.

3. Nirav P Pandya, Sweta B. Prajapati, Sanjay J. Mehta, Kunjan M. Kikan, Pratima J. Joshi etal 2011. Evaluation of various methods for detection of metallo- $\beta$-lactamase $(\mathrm{mbl})$ production in gram negative bacilli. Int $\mathbf{J}$ Biol Med Res, 2(3) :775 - 777.

4. Marie-vic O.Raco and Mario Y vette C.Barez. 1998.Profile of Community Acquired Urinary tract Infections in Davo City . Journal of Infectious Diseases , 27 (2) : 62-66.

5. K.Gupta, Delie schools, Water E, Stamm.1999.Increasing prevalence of Antimicrobial Resistance Among Uropathogens causing Acute Uncomplicated cystitis in Women . Journal of American Medical Association, 281 ( 8 ) : $736-737$.

6. Katarzyna Hryniewicz, Katarzyna Szczypa, etal 2000. Antibiotic susceptibility of bacterial strains isolated from urinary tract infections in Poland .J. Antimicrob. Chemother. 47 (6): 773-780.

7. V.Gupta, A Yadav, RM Joshi RM.2000 .Antibiotic resistance pattern in uropathogens. Indian j Med Microbiology $2000 ; 20: 96-8$.

8. Carter, M. W., Oakton, K. J., Warner, M. \& Livermore, D. M.2000. Detection of extended-spectrum $\quad \beta$-lactamases in klebsiellae with the Oxoid combination disc method . J Clin Microbiol, 38 : 4228-4232.

9. Florijin, A, Nijssen S, Smitz F, Verhoef J, Fluit A 2002. Comparison of E - test and double disk diffusion test for the detection of extended spectrum beta lactamases ." European Journal of Clinical Microbiology and Infectious Diseases. 23 ( 2 ) : 186 190.

10. Hanan A. Babay, MD KSF Path et al.2002. Detection of Extended spectrum beta lactamases in Enterobacteriacea at a teaching hospital Saudi Medical Journal, 23 ( 2 ) : $186-190$.

11. T.S.Dimitrov E.E M.Meagra F. Awni .2003.Etiology and Antibiotic susceptibility Pattern of Community acquired Urinary trat infections in a Kuwait Hospital.Medical Princples and Practice 13 : 334 -339.

12. Josh Anastacio Dias Neto, Antonio Carlos Pereira martins, Leonardo Dias Magalhaes da Silva etal .2003. Community acquired urinary tract infection : etiology and bacterial susceptibility. Acta Cirurgica Brasileira , 18 ( 15 ) : 33 -36.

13. K.Jabeel, A. Zaffar, R.Hassan.2003. Comparison of double disc diffusion test and combined disk method for the detection of extended spectrum beta lactamases in Enterobacteriaceae. Journal of Pakistan Medical Association . 53 ( 11 ) : 534 - 536.

14. Supriya S. Tankhiwale, Suresh V. Jalgaonkar, Sarfraz Ahamad \& Umesh Hassani .2004. Evaluation of extended spectrum beta lactamase in urinary isolates. Indian J Med Res ,120: 553-556.

15. Vikas Manchanda and Narendra P. Singh. 2003. Occurrence and detection of Amp c beta lactamases amonggram negative clinical associates using a modified three dimensional test at Guru Tegh Bahadur Hospital . Journal of Antimicrobial Chemotherapy, $51: 415-418$.

16. Ruksha, H Srinivasa , R S Macaden.2003.Occurence and characterization of uropathogenic Escherichia coli in urinary tract infections . Indian Journal of Medical Microbiology. 21 ( 2 ) : 102- 107.

17. Sheung-Mei Lau, Ming - Yieh peng, Feng Yee Chang .2004. Resistance rates to commonly used antimicrobials among pathogens of both bacteremic and non 
bacteremic community acquired urinary tract infections. Journal of Microbiology, Immunology and Infection. 37 : $185-191$.

18. Chitra-Yengkokpam, Dyanand Ingudam, Ibotomba Singh Yenkapamand Byway Kumar Jha.2002. Antibiotic Suscetibility Pattern of Urinary Isolates in Impearl ( Manipur ) India. Journal of Nepal Medical College . $1-2$.

19. Loren. G Miller and Angela W. Tang.2004. Treatment of Uncomplicated Urinary tract infections in an era of antimicrobial resistance . Mayo Clinical Practice, 79 ( 8 ) : 1048 -1054

20. J. I Alos., M.G.Serrano, J.I.Gomez - Garces and Perianes. 2005 .Antibiotic resistance of Escherichia coli from community acquired urinary tract infections in relation to demographic and clinical data. Clinical microbiology and Infection. 11:199 - 203.

21. Ansbach, Robert K , Dybus, Karen , Bergeson, Rachel.2005. Uncomplicted E.coli urinary tract infection in college women : A follow up study of E.coli sensitivities prescribed antibiotics, Journal of American College, $1-3$.

22. Jennifer A. Black, Ellen Smith Moland and Kenneth S. Thomson.2005.AmpC Disc Test for Detection of Plasmid-Mediated AmpC $\beta$-Lactamases in Enterobacteriaceae Lacking Chromosomal AmpC $\beta$ Lactamases. J. Clin. Microbiol. 43( 7 ) :3110-3113.

23. Clare Franklin, Lisa Liolios, and Anton Y.2006. Peleg.Phenotypic Detection of Carbapenem-Susceptible MetalloLactamase-Producing Gram-Negative Bacilli in the Clinical Laboratory.Journal of Clinical Microbiology . 44(9): 3139-3144.

24. Gupta V, Datta P, Chander J .2006. Prevalence of metallo-beta lactamase (MBL) producing Pseudomonas spp. and Acinetobacter spp. in a tertiary care hospital. Indian J Infect.;52(5):311-4.

25. Amita Jain \& Rajesh Mondal.2007. Detection of extended spectrum b-lactamase production in clinical isolates of Klebsiella spp Indian J Med Res .127: 344-346.
26. Habeeb Khadri, Mohammed Alzohairy.2007. High prevalence of Multi drug resistance ( MDC) and extended spectrum beta lactamase among community acquired Urinary tract infection (CAUTI). Journal of Bacteriology Research. (9) :105110.

27. Irene Galani, Panagiota Danai Rekatsina, Despina Hatzaki, Diamantis, Maria souli, Helen Giamarellou.2007.Evaluation of different laboratory tests for the detection of MBL production in Enterobactericea. Journal of Antimicrobial Chemotherapy, 3 : $548-53$.

28. Wonkeun song, II K won Bae, You - Nae Lee, Sang Hee Lee, and Seok Hoon Jeong.2007. Detection of ESBL by using boronic acid as an Ampc $\beta$ lactamases inhibitor in clinical isolates of Klebsiella spp. and Escherichia coli.. Indian Journal of Clinical Microbiology. 7 : 1180 -1184.

29. Christian G Giske, Bjorg Haldorsen, Eirik W Lundblad, Bettina Aasnaes, Lina Bylund, Phion HO etal "Phenotypic Detection of Amp C : Comparison of E test Amp C Strips and Disk Synergy Assays with cloxacillin, Boronic Acid and EDTA.'Karolinska Institutet-MTC / Karolinska University Hospital.; Poster : 871.

30. VSamuel Kariuki, John kiiru, Joycemwituria , Gunturu Revathi, John Corkill .2007. Escherichia coli from community acquired urinary tract infections resistant to fluoroquinolones and Extended beta lactams . Journal of Infection in Developing Countries . 1 ( 3 ) : 257 -262.

31. VAnkur Goyal, Amit Prasad, Ujjala Ghoslal, K. N Prasad .2008. Comparison of disc diffusion, disc potentiation \& double disc synergy methods for detection of Extended spectrum beta lactamases in Enterobacteriaceae . Indian Journal of Medical Research, $1-3$.

32. Nachimuthu Ramesh , Chettipalayam Samiappan Sumathi, Velramar Balasubramanyam and Velu rajesh Kannan .2008. Urinary tract infections and Antimicrobial susceptibility pattern of 
Extended spectrum beta lactamases producing clinical isolates. Journal of Advances in research, 2(5-6):78-82.

33. Yohei Doi, Brian A potoski, Jennifer M. Adams - Haduch, Hanna E. Sidjabat, Anthony W. pasculle, and David L. Paterson .2008. Simple disc based method for detection of Klebsiella pneumoniae carbapenamase type beta lactamase by use of a Boronic Acid compound .Journal of clinical microbiology .4083 - 4086.

34. M.J.C. Noyal, G.A. Menezes, B.N. Harish, S. Sujatha \& S.C. Parija .2009. Simple screening tests for detection of carbapenemases in clinical isolates of nonfermentative Gram-negative bacteria. Indian J Med Res .129: 707-712.

35. A Manoharan Chatterjee S, Mathai D, SARI Study Group. 2010. Detection and characterization of metallo beta lactamases producing Pseudomonas aeruginosa. Indian J Med Microbiol.28:241-4.

36. Durgesh Gopalrao Deshmukh, Ajit S Damle, Jyoti K Bajaj, Jayshree B Bhakre, Neeta S Patwardhan .2011. Metallo- $\beta$ lactamase-producing Clinical Isolates from Patients of a Tertiary Care Hospital.J Lab Physicians. 3(2): 93-97.

37. D

Maraskolhe,V.S.Deotale,D.k.Mendiratta and P.Narang.2014.Comparision of three laboratory tests for detection of Ampc beta lactamases in klebsiella species and Escherishia coli.Journal of clinical and diagnostic research.8(6).
38. Sasirekha Bakthavatchalu, \&, Uma Shakthivel, Tannu Mishra .2013. Detection of ESBL among ampc producing enterobacteriaceae using inhibitor-based method . The Pan African Medical Journal.14:28.

39. J.Gerald Colle, Barrie P.Marmion, Andrew G. Fraser , Anthony Simmons.1996.Practical Medical Microbiology $14^{\text {th }}$ Edition Singopore : Longman Singapore Publishers .

40. Mohammed Akram, Mohammed Shahid and Asad u khan .2007.Etiology and antibiotic resistance pattern of community Acquired urinary tract infections in JNMC Hospital Aligarh, India . Journal of Annals of clinical Microbiology and Antimicrobials . 6:4.

41. Asad u Khan and Mohd S Zaman.2006. Multiple drug resistance pattern in urinary tract infection patients in Aligarh.Journal of Indian Medical Biomedical research, 17(3):1-5.

42. Shukla, R.Tiwari, M. Agrawal. Prevalance of Extended spectrum beta lactamase production Klebsiella pneumonia in a tertiary care hospital .2004. Indian journal of Medical Microbiology.54:684-687.

43. Anand Manoharan, Madhan Sugumar, Anil Kumar, Hepzibah Jose, Dilip Mathai .2012. Phenotypic \& molecular characterization of AmpC $\beta$-lactamases among Escherichia coli, Klebsiella spp. \& Enterobacter spp. from five Indian Medical Centers . Indian J Med Res.135: 359-364.

\section{How to cite this article:}

Fatima Amatullah, Gandham Pavani and Nandeshwar A.J. 2017. Detection of ESBLs, MBLs and AmpCs in Gram Negative Uropathogens in Tertiary Care Hospital. Int.J.Curr.Microbiol.App.Sci. 6(11): 1594-1604. doi: https://doi.org/10.20546/ijcmas.2017.611.191 